SHS Web of Conferences 24, 01006 (2016)

DOI: $10.1051 /$ shsconf/20162401006

(C) Owned by the authors, published by EDP Sciences, 2016

\title{
Research and analysis of contradictions and strategies of Hainan tourism development under the new normal background
}

\author{
Xiangxiang Xie \& Shichen Fan \\ School of Tourism, Hainan University, Haikou, Hainan, China
}

\begin{abstract}
At present, China's economic and social development has entered into a new normal state, the construction of Hainan international tourism island also has entered into the middle and late period. Hainan tourism has made brilliant achievements, but the development contradictions have become increasingly serious. Based on the analysis of the current situation and realistic problems of Hainan tourism, this paper points out five principal problems of Hainan tourism development--industrial status, supply-demand relationship, cultural preservation, subject-object relationship and government-business relationship, and it also proposes strategic suggestions on the great tourism, large interconnection, great culture, big Hainan and big special zone.
\end{abstract}

Keywords: new normal state; tourism; industry contradiction; tourism +; Internet +

\section{BASIC STATUS OF HAINAN TOURISM DEVELOPMENT UNDER THE NEW NORMAL STATE}

(1) The industrial status continues to be improved and the industrial scale continues to be expanded

The province continues to accelerate and promote the construction of the international tourism island, deepen the reform of the tourism management system, speed up the construction of key projects of the tourism and strengthen the tourist source market development and tourism promotion, so that Hainan tourism market has achieved rapid development, and the number of tourists and tourism income remain a rapid growth with a double-digit rate. In 2014, Hainan province receives $47,890,800$ domestic and foreign tourists with a year-on-year growth of $10.6 \%$. Among them, it receives $40,601,800$ overnight tourists with a year-on-year growth of $10.56 \%$ and 7,289,000 tourists of one-day tour with a year-on-year growth of $10.7 \%$; a total annual tourism income is 50.653 billion with a year-on-year growth of $13.2 \%$; the growth rate of the total number of tourists reception and total tourism income is higher than the average level of the national tourism development. The added value of tourism in the whole province is 25.81 billion, accounting for $7.4 \%$ of the GDP proportion in the whole province; the added value of the tertiary industry with the tourism as a leading industry accounts for $51.9 \%$ of the GDP proportion in the whole province. The annual growth rate of the tourism is $9.1 \%$. Thus, the industrial status and industrial scale of tourism continues to be improved and expanded during the economic and social development in Hainan.

(2) The industrial system continues to be enriched, and the industrial function is improved gradually

After several years of development, Hainan tourism with rich tourism resources has established a system of traditional industrial factors such as food, transportation, travel, visit, shopping and entertainment, and it also made a breakthrough in business, health maintenance, learning, leisure, emotion, novel exploration and other new industrial factors. Besides, the rural tourism market is greatly developed in Hainan, and the duty-free shopping, the drawback, the cruise and yacht, the wedding travel, the parent-child travel and other new tourism products are also constantly furthered in Hainan. The economic function of tourism industry is gradually enriched. Meanwhile, the tourism development effectively promotes the reform and development of urbanization, which plays a positive role in enhancing the touristic awareness of the residents, service philosophy and international mindedness.

(3) The industrial policies are constantly introduced, and the industrial environment continues to be optimized

This is an Open Access article distributed under the terms of the Creative Commons Attribution License 4.0, which permits unrestricted use distribution, and reproduction in any medium, provided the original work is properly cited. 


\section{SHS Web of Conferences}

After the construction of Hainan international tourism island upgrading as a national strategy, Hainan tourism significantly accelerates the pace of promoting development by opening-up. The visa-free entry, duty-free departure, departure drawback, cruise and yacht, low-altitude travel, uninhabited island development policy, exhibition reward policy, Internet development and other preferential policies have been in a trial implementation stage, which have achieved a good boosting effect. The introduction and implementation of the industrial policies not only enrich the tourism product system, but also promote the reform and opening-up of the tourism system, expand and optimize the tourism development space; what's more, these policies promote the innovative development of various types of business, so that the overall environment of the tourism market has been improved and optimized.

\section{REALISTIC PROBLEMS OF HAINAN TOURISM DEVELOPMENT UNDER THE NEW NORMAL BACKGROUND}

From the perspective of in-depth development, Hainan tourism development has made a considerable progress and better achievement; but from nationwide horizontal comparison, Hainan tourism belongs to the bottom zone no matter from the quantity of tourists reception, or the total tourism income, which is only higher than Tibet, Qinghai, Ningxia and other western provinces with the total tourism income which is less than 50 billion. For Hainan, the regional advantage fails to convert into the market advantage, the resource superiority fails to effectively convert into the market advantage, and the system superiority fails to effectively convert into the system superiority, relatively rich tourism resources and unique regions. This result and performance are not very ideal. So what are the difficulties and challenges for the Hainan tourism development? Generally speaking, three major problems of Hainan tourism development are as follows: The tourist accessibility is weak; the tourist traffic service system is imperfect; the power of tourist consumption is not fully released.

(1) The international tourist accessibility has not made a fundamental breakthrough

In 2014, the whole province receives a total of 661,400 inbound overnight tourists with a year-on-year decrease of $12.6 \%$. Among them, it receives 421,500 foreigners with a year-on-year decrease of $12.6 \%$ and 239,900 compatriots in Hong Kong, Macao and Taiwan with a year-on-year decrease of $6.3 \%$. The inbound tourism market continues to decline, which is certainly affected by the world economic downturn and the impact of the Southeast Asian tourism market, but also due to Hainan itself, and mainly because visa-free policies fail to be fully implemented and the international routes fail to be matched. The state attaches great importance to the development of Hainan and offers a series of convenient immigration policy to Hainan, in which the greatest impact is the visa-free entry policy of the tour group. In China, currently, the visa-free entry policy of 26 countries is the most convenient and most open entry visa policy. However, the visa-free policy of 26 countries only applies to the visa-free group of 26 countries in direct flight from the foreign countries to Hainan, but the foreign tourists in transit from other domestic cities to Hainan could not enjoy the visa-free policy. It implies that among 26 countries, countries that are free of direct flight with Hainan cannot apply this policy and directly fall into a dilemma- "visitors flood toward the tourist destination but forbidden". So far, Meilan Airport in Haikou and Phoenix Airport in Sanya only open up direct routes with Russia, South Korea, Singapore and other minority countries, which affect the effective implementation of the visa-free policy of 26 countries to a large extent. Except for the number of Hainan visa-free entry tourists in Russia, Singapore and other minority countries, the number of tourists in other countries is few. Meanwhile, how to make full use of Beijing, Shanghai, Guangzhou and other big cities to implement 72-hour visa-free entry policy and win more international tourists for Hainan also must be addressed.

(2) The tourist traffic system with the service object of individual tourist has not made a breakthrough

With the continuous improvement of the publicity of Hainan and the transformation of public awareness of vacation tour, the individual tourist market has become a dominant position of Hainan tourism. The sampling survey shows that in the first half of 2015, the proportion of individual tourist in Sanya reached $75 \%$, and the independent travel, lover travel, depth travel, family travel and other new forms of tourism constantly emerged. Among them, nearly half of tourists are regular and frequent tourists of Sanya. Sanya resort in all types of holidays has become an important choice of many Chinese families. These tourists during holiday are not only satisfied with the tourist attraction of Sanya, but also have a keen interest on the surrounding cities and counties, and even the provincial capital, Haikou. The short-distance travel routes across the city and county and featured products are the pursuit of the individual tourist market. However, since the traffic management system of Hainan Province has been limited to block segmentation in the cities and counties, and the taxis and tourist vehicles that include one-day tour vehicles fail to implement trans-regional service and business, so the tourists usually enjoy holiday travel in the surrounding cities and counties in a way of "being forced to change vehicles" or "taking unlicensed taxis". Such experience greatly affects the tourist willingness and ability to carry out surrounding travel and also enormously 
wastes hard-earned high-quality tourist sources, falling into a dilemma-"available vehicles could not run". Although a number of special lines are launched through coordination with the provincial government, the operation mode which featured with small quantity, long time and fixed line could not meet the basic needs of the tourist traffic services. In the stark contrast, the tourist vehicles in five provinces of the East China are unimpeded, while the EU tourist vehicles can provide transnational services.

(3) The consumption potential of tourist characterized with shopping cannot be truly released

For quite a while, Hainan tourism is in an embarrassment condition, namely "many hands cannot provide much money". In 2014, the whole province receives $40,601,800$ overnight tourists, the overnight tourism income is 48.498 billion yuan and the consumption per capita is only 1,194 yuan. However, compared with the consumption level of outbound tourism which is more than 10,000 yuan, it can be called as "a giant in the presence of a super-giant (which means the price of this kind tourism is quite lower than that of outbound tourism by comparison)". The core reason for low consumption per capita is that the tourist's consuming willingness is limited, in which the duty-free shopping policy is the most prominent. On March 24, 2011, the Ministry of Finance issued a Notice on Implementation of Hainan Island Tourist Duty-free Shopping Policy Pilot. Hainan pilot program started to execute offshore duty-free policy of limited channel, limited time, limited value, limited quantity and limited variety since April 20, 2011, which really played a role in stimulating Hainan tourism in the initial period of policy implementation. However, the proportion of the self-help tourists for holiday leisure increases year by year with the increase of national income. Evidently, the duty-free policy characterized by "five limitations" is unable to meet the tourist's consuming willingness, and the tourists generally have a disharmonious sense of "money cannot be spent". In addition, Hainan tourism is also not perfect in the supply and quality of the catering, entertainment, recreation and experiential consumption, and it is unable to meet all-around consumption needs of the tourists.

\section{PRINCIPAL CONTRADICTIONS OF HAINAN TOURISM DEVELOPMENT UNDER THE NEW NORMAL BACKGROUND}

(1) Industrial contradiction: the tourism industry as a strategic pillar industry fails to be fully embodied For a long time, the contradictions between the tourism industry and other industries have not been effectively alleviated. In particular, the contradictions between the tourism industry and the real estate industry are increasingly serious. The real estate characterized with "short-flat-fast" forms a huge crowding- out ad- vantage for the tourism industry characterized with "long-hollow-slow" in terms of land, capital, policy and other aspects. The specific manifestation is that the water bodies, mountains, forests, greenbelts, wetlands, beaches, bays, islands, reefs and other non-renewable holiday tourism resources with coast, river, lake, port, hillside, island and other great landscape values are substantially occupied by the real estate projects, resulting in very limited reserved development space in the subsequently high-end holiday tourism industry. In the last decade, the total amount and growth rate of real estate investment in Hainan is increased rapidly. In various cities, counties and bay areas, the real estate investment and construction are in full swing, skylines in the cities and towns often create a new high, the scale of real estate in stock increases day by day, the scarce resources perish rapidly, and Hainan, the internationally touristic island, also becomes an "island of real estate", which generates a great impact on the tourism industry. In stark contrast, there are few tourism investment projects and tourist attractions, or even fewer construction of the tourism cultural landscape in the last decade. Thus, the tourism industry fails to perform its position and effect as a strategic pillar industry.

(2) Contradiction between supply and demand: the existing tourism supply system fails to effectively meet the individual needs of the public on vacation Objectively speaking, except for the sun, sand, seawater and other natural resources and tourist accommodation services, the tourism of Hainan fails to form sufficient features and brands in terms of food, vehicle, travel, visit, shopping, entertainment and other factors in the tourism industry. In terms of food, it is still subject to four traditional famous cuisines in Hainan, and the new brand of island food has not yet formed; in terms of transportation, it fails to establish convenient and efficient tourist traffic service systems, nor meet high-end vehicles of the high-end tourists; in terms of travel, The ends of the earth tour area and Nanshan are still the major scenic spots, while the tropical paradise and Yanoda or other emerging scenic spots have not yet reached the extent of leading and representing Hainan; in terms of shopping, although there are drawback and duty-free policies, the implementation plan for the limited quota, limited time, limited quantity and limited variety greatly suppresses the shopping willingness; in terms of entertainment, although there is a relatively successful play-Sanya Eternal Love, the ending of Impression Hainan Island and Begonia Show is particularly embarrassed for just a few like them. With the introduction and emerging of business, learning, health maintenance, leisure, emotion, novel exploration and other new industrial factors, the development of cruise and yacht, low-altitude travel, marine tourism and other new forms of business remains to be seen. 
(3) Cultural contradiction: contradiction between the ever-growing cultural consumption demand and the rapidly vanished cultural resources

Culture is the soul of tourism while tourism is the carrier of culture. Without culture, tourism is not viable. With the enhancement and development of tourism awareness, the tourist curiousness to the local culture and exploratory willingness is more intense with an ever-growing cultural consumption demand. However, as a sole tropical island in China, Hainan has its unique tropical culture dominated by the rainforest, marine culture dominated by the shoreline and water bodies, ethnic culture dominated by the $\mathrm{Li} \mathrm{Na}-$ tionality and civil culture dominated by the living style of islanders, which are experiencing reality and helpless of accelerating elapse. Taking the ethnic culture of Li Nationality as an example, many villages of Li Nationality basically vanish with the advent of new urbanization wave, and its unique food, architecture, music, clothes and external carriers also vanish with the resident assimilation of Li Nationality and depression of the villages of Li Nationality.

Currently, only the Cultural Tourism Zone of Betelnut Valley in Baoting County preserves the culture of $\mathrm{Li}$ and Miao Nationalities and arranges them to display, which becomes a living specimen of the local culture in Hainan and achieves good economic and social benefits.

(4) Contradiction between subject and object: disharmony between protection of legitimate rights and interests of tourists and growing interest demands of residents

With the rapid development of tourism and real estate, the local residents of Hainan Island rapidly form a state of differentiation. A part of residents are on the way of prosperity due to the land transfer, housing demolition, abandoning farming and fishing to engage in the tourism industry and other ways, while a part of residents are on the way of decline or even poverty due to the territory loss and poor management. Meanwhile, due to the entry of a lot of migrants outside the island compete in the market, a sense of unfairness and dissatisfaction of the residents becomes increasingly prominent. The illegal business of "depending on the tourists to make a living" is widespread, and the non-credit services of deceiving tourists are also widespread, which directly result in varying degrees of innocent infringement on the lawful rights and interests of the tourists, exerting a significant negative impact on the satisfaction of tourists and badly damaging the image of this tourism city.

(5) Contradiction between government and business: the government management system and mechanism as a whole obviously lags behind the market demand With the gradual deepening of the reform and opening-up all over the world and determination of the market as a decisive position of resource allocation, under the baton of the market, the land, capital, technology, talent and other production factors are constantly integrated and optimized in all fields of the tourism industry, and actively seek for the best investment areas, and exert the best combined effect. However, the government-oriented tourism development strategy greatly hinders the development of Hainan tourism market under the new situation. In particular, unified scheduling of the tourist traffic, local protection of the traffic in cities and counties, prohibition of the travel agents to own tourist vehicles, abnormal employment of tour guides, supervisory localization of the tourism market and limited role of the tourism industry association result in poor experience of the tourist traffic services, travel agencies failure in growing stronger and larger, tour guide's commission being out of control, fragmentation of the market supervision, weak development of industry association and other non-market phenomena, and failure in effectively restraining and improving industrial illnesses in the development of tourism industry, which directly evolve into a damage to Hainan tourism industry and result in worsening business environment.

\section{PRIMARY STRATEGIES OF HAINAN TOURISM DEVELOPMENT UNDER THE NEW NORMAL BACKGROUND}

(1) Actively promote the industry space expansion of "great tourism +"

To achieve this goal, we should actively promote the multi-element integration between the tourism and related industries, between the types of business in the tourism industry, and between the tourism and countries, and we should also promote the innovation with different types of business, products, services, management and marketing and the integration of regional resources, elements and space with the starting point of multi-element integration. Then we can create a beatific Hainan through boosting the overall transformation and upgrading of the tourism, playing the role of tourism to benefit people and building a harmonious host-visitor relationship.

The specific measure is to push forward the integrative development of "tourism + real estate", "tourism + health care", "tourism + cultural industry", "tourism + sport industry", "tourism + exhibition industry", "tourism + trading business", "tourism + marine industry", "tourism + featured agriculture", "tourism + gaming industry" and other industries with the tourism as a core, and "tourism $+\mathrm{X}$ " as a main mode, so as to constantly innovate the types of tourism business and enrich travelling experiences of the tourists.

(2) Actively promote the network space expansion of "large interconnection +"

To this point, first, we should actively introduce pro- 
fessional Internet organizations and well-known companies and fully rely on the Internet technology to nurture local tourism e-commerce and other new types of Internet tourism, and fill up the domestic and foreign blanks of new types of Internet business; second, we should actively introduce professional Internet operation personnel to transform the operation pattern and profit model of the hotel, scenic spot, travel agency, restaurant and other traditional types of tourism business, research and develop innovative operation pattern and profit model of the Internet tourism, and gradually transplant into a brand new type of Internet tourism, and seize the new type of Internet tourism; finally, we should make full use of borderless advantages of the Internet to strengthen cultural exchanges and tourism cooperation between Hainan and different levels of areas.

(3) Actively promote the culture space expansion of "great culture +"

In order to achieve this target, we should establish non-reproducibility and scarcity concept of the cultural resources of Hainan, and establish Hainan local culture survey system, red line system and monitoring system, so as to practically protect the tropical rainforest culture, marine ecological culture, folk culture and lifestyle of Li Nationality, as well as culture carrier and pattern of manifestation of tourism development. Based on emphasizing the authenticity and origin of culture, with the carrier of rural tourism, to develop the cultural experience point and experience area of Hainan tropical islands step by step. Meanwhile, for Hainan Island as the international multicultural exhibition center and experience center, to absorb representative international cultural resources with the historical heritage value, expand development space of Hainan local culture, and promote exchange and blending of domestic and foreign culture in Hainan Island.

(4) Promote the geographic space expansion of "big Hainan+" actively

The first goal to achieve is the integration of internal space. We should integrate and optimize the internal industrial layout, strengthen the spatial concentration and clear the regional division and cooperation. Moreover, we should take the initiative to interconnect, excavate the North and South Area, sea, land and air tourism development space and fully release the potential energy of the internal tourism development space in Hainan. The second goal is outer space integration in the province. We should continue to promote the construction of the "tourism circle of big Hainan", so as to form a system of tourism space structure that regards Hainan as the center and then extends over the surroundings, thus demonstrating the potential advantages of space in surrounding areas. The third is cross-regional space integration. Under the new situation, to firmly grasp the national strategic opportunity of "Maritime Silk Road of the $21^{\text {st }}$ century", actively take effective measures to seek for cultural exchanges and economic and trade cooperation with the countries or areas along the South China Sea and Maritime Silk Road, so as to achieve a fundamental breakthrough in the cross-regional tourism planning, tourism management, tourism route development, tourism marketing, tourism think tank, tourism investment and other fields, and gradually build Hainan as a strategic fulcrum of the tourism development on the Maritime Silk Road of the $21^{\text {st }}$ century and tourists collecting and distributing center of the international silk road.

(5) Promote the system space expansion of "big special zone +" actively

Hainan is China's largest special economic zone, which ranks the top in in many fields of China and around the globe with creativity and pioneering. In particular, in terms of policy, it can further give full play to the advantage of special zone and comprehensively clear up the system barrier and bottleneck and mechanism illness in the development of tourism industry. To take the lead in creating policy breakthrough and system innovation in the accessibility of the cities and counties, tourist traffic marketization, public service system, tourism enterprise diversification, three-dimensional product space and other aspects to respond the consumption demand of the public holiday travel and the era of individual tourists, integrate interests and resources of the government decision-making bodies, tourism administrations, tourism industry associations, tourism enterprises, tourists and residents and other stakeholders to a maximum extent, and explore a sustainable development road of Hainan tourism under the new normal state.

In short, through the implementation of strategic measures of the industry space, network space, culture space, geographic space and system space, and full implementation of "tourism +" and "Internet +" national strategy, we should integrate the industrial resource elements, promote the transformation and upgrading, quality and effect improvement of the whole chain of tourism industry. What' more, we should effectively protect and promote the local culture of Hainan, systematically optimize the environment of tourism development, expand the tourism industry, enhance the contribution of economic and social development and strengthen the power of Hainan. Meanwhile, we should comprehensively promote cross-industry integration, exert advantages such as the wide range of tourism correlation and the great driving forces, enhance the leading role of the tourism industry, increase the efforts of cultural protection and system innovation, and achieve the goal of strategic leading industry status of tourism in the national economic and social development of Hainan under the new normal state. 


\section{SHS Web of Conferences}

\section{ACKNOWLEDGEMENT}

This paper is financially supported by the Scientific Research Project of National Tourism Administration (GN: TYETP201337-2, GN: 2015(ZD)-4) and the Key and Special Project of Social Science, Hainan Province (GN: HNSK (ZD)-A1).

\section{REFERENCES}

[1] Cao Qiuxiu. 2015. New Opportunity of Hainan Tourism under the Perspective of "One Belt and One Road" - Interview with Vice President of China Tourism Academy, Zhang Dong. Hainan Today, 02: 10-12.
[2] He Zhixia. 2013. Current Situation and Countermeasures of Hainan Tourism Service Trade - A Survey based on Initial Period of Construction of Hainan International Tourism Island. Contemporary Economics, 22: 104-105.

[3] Cao Xiang. 2014. An Empirical Research of International Competitiveness of Hainan Tourism Service Trade and its Influence Factors. Tourism Research, 03: 59-64.

[4] Liu Zhaoxia. 2013. Research of Current Situation and Countermeasures of Hainan Tourism Development. Science and Technology Information, 06: 54.

[5] Gong Jian, Li Miao, \& Hu Jing. 2012. Research of Development Pattern of Hainan International Tourism Island. Journal of Zhongnan University of Economics and Law, 05: 15-20.

[6] Chen Ganghua. 2012. Tourism Penetration of Island Destinations - Hainan Case and International Comparison. Tourism Tribune, 11: 72-80. 